MATEC Web of Conferences 37, 01044 (2015)

DOI: $10.1051 /$ matecconf $/ 20153701044$

(C) Owned by the authors, published by EDP Sciences, 2015

\title{
COMBUSTION OF METHANE-OXYGEN MIXTURE IN STEAM ATMOSPHERE
}

\author{
N.A. Pribaturin, A.R. Bogomolov ${ }^{1}$, S.S. Azikhanov ${ }^{2}$, S.A. Shevyrev ${ }^{3 a}$ and K.O. Kirilov ${ }^{3}$ \\ ${ }^{1}$ Kutateladze Institute of Thermophysics SB RAS, 630090 Novosibirsk, Russia \\ ${ }^{2}$ Kuzbass State Technical University named after T.F. Gorbachev, 650000 Kemerovo, Russia \\ ${ }^{3}$ National Research Tomsk Polytechnic University, 634050 Tomsk, Russia
}

\begin{abstract}
Combustion of CH4:O2 mixture in the medium of low-potential steam was studied experimentally. Results of composition combustion products are presented. It is shown that they depend on the ratio of flow rates of gas mixture and steam.
\end{abstract}

\section{Introduction}

Now the modern thermal power plants (TPP) operating at supercritical steam parameters, are among the most promising areas of research, design and construction in the field of power equipment. This is because such TPPs allow a significantly increase in the efficiency of power generation, and, hence, a significant reduction of environmental pollution. In the European Union, it is planned to introduce coal-fired power units with the efficiency of about 53-54\% [1].

In the development of highly efficient power units, two areas of technical issues that should be considered at their design can be distinguished:

- development of construction materials for turbines, which can stand the pressure of up to $37.5 \mathrm{MPa}$ and temperature of up to $700^{\circ} \mathrm{C}$ and higher;

- technology of steam superheating to the required parameters.

The first task is now successfully solved, at that, the materials, which can stand the required parameters, have been already created and the availability of the turbine is high.

The second task is being developed through production of superheated steam by means of the combustion product of gas mixture $\mathrm{CH}_{4}+\mathrm{O}_{2}$ :

$$
\begin{aligned}
& \mathrm{CH}_{4}+2 \mathrm{O}_{2}=\mathrm{CO}_{2}+2 \mathrm{H}_{2} \mathrm{O}+\mathrm{Q} \\
& \mathrm{CH}_{4}+\mathrm{O}_{2}=\mathrm{CO}+\mathrm{H}_{2} \mathrm{O}+\mathrm{H}_{2}+\mathrm{Q} \\
& \mathrm{CH}_{4}+0,5 \mathrm{O}_{2}=\mathrm{CO}+\mathrm{H}_{2}+\mathrm{Q} \\
& \mathrm{CH}_{4}+\mathrm{H}_{2} \mathrm{O} \leftrightarrow \mathrm{CO}+3 \mathrm{H}_{2}
\end{aligned}
$$

When analyzing publications, it was determined that the main works are being performed using the methane-air mixtures in the presence of microdroplets of water and mist [2]. But there are no studies on combustion of methane-oxygen mixture in the atmosphere of low-temperature steam.

\section{Problem statement}

The current work is aimed at production of superheated steam using methane and oxidizer-oxygen as a fuel gas, determination of temperature parameters of combustion products and their composition in a certain range of metering characteristic of the gas mixture and steam.

\section{Results and discussion}

The experiments were carried out for the excess oxidant ratio close to 1 . The combustion chamber (steam superheater) is made of stainless steel, where the cocurrent flows of streams of steam and combustion products of the methane-oxygen mixture move.

\footnotetext{
${ }^{\text {a }}$ Corresponding author : wevelev@tpu.ru
} 


\section{MATEC Web of Conferences}

The scheme of experimental setup for studying the regimes of combustion of methane/oxygen mixture in the atmosphere of low-temperature steam with production of high-temperature steam is shown in Figure 1.

The length of steam superheater is $200 \mathrm{~mm}$, inner diameter is $20 \mathrm{~mm}$, and material is stainless steel. During the experiments the following parameters were controlled: flow rate and temperature of gas mixture components at the reactor inlet, steam flow rate and temperature, temperature, volume and concentration of exhaust gases. The parameters were registered automatically.

As a result of mixing of the products of gas mixture and steam combustion in the superheater combustion, superheated steam, containing gas admixtures, was obtained $\left(480-600^{\circ} \mathrm{C}\right)$ at the atmospheric pressure. Then, the mixture of gases passed through the condenser-separator, where water vapors were condensed, and entered the flow gas analyzer through the moisture separator. The measurement error for the component concentrations did not exceed $5 \%$.

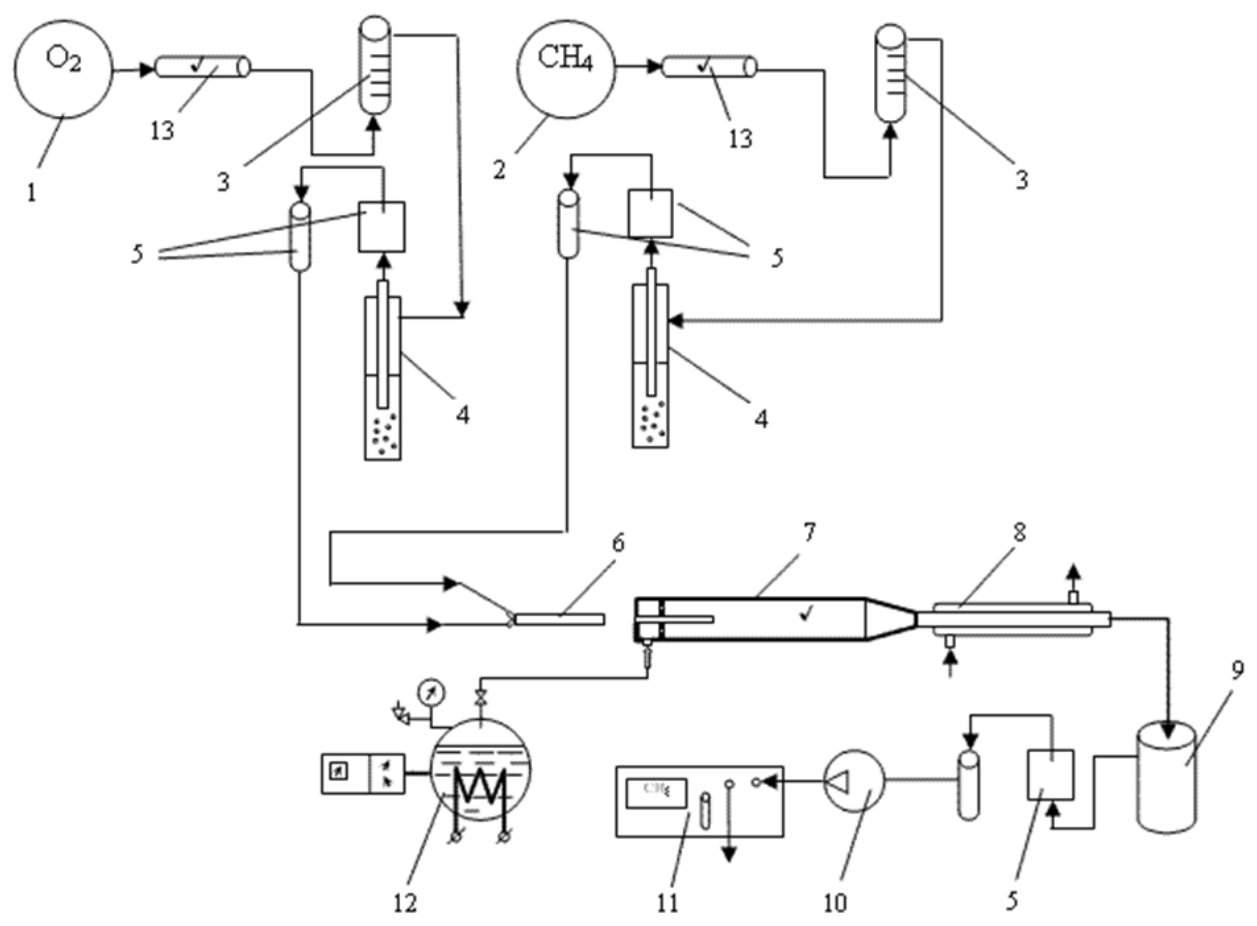

Figure 1. Scheme of experimental setup: 1 - vessel with $\mathrm{O}_{2} ; 2$ - vessel with $\mathrm{CH}_{4} ; 3$ - gas flow meters; 4 - flame arrester; 5 - vessel for gas dewatering; 6 - gas burner; 7 - steam superheater (combustion chamber); 8 - condenser; 9 - vessel for separation of gas and liquid products; 10 - compressor; 11 - gas analyzer; 12 - steam generator; 13 - gas temperature recorder.

The reaction of methane combustion can occur by equation (1) at the stoichiometric ratio or oxidizer excess, or by equations (2) and (3) at its shortage, reaction (4) can also occur. Methane steam reforming occurs in a wide range of temperatures by one of the main chemical reactions (4) [3]. This reaction can occur not only in the immediate zone of steam mixing at the boundary of the flame surface with the combustion products of methane-oxygen mixture, but also behind the flame front in the combustion chamber. It is necessary to investigate the conditions of gas mixture combustion in steam to reduce the hydrogen content.

Dependence of gas composition on the relative flow rate of gas mixture is shown in Figure 2. 


\section{Smart Grids 2015}

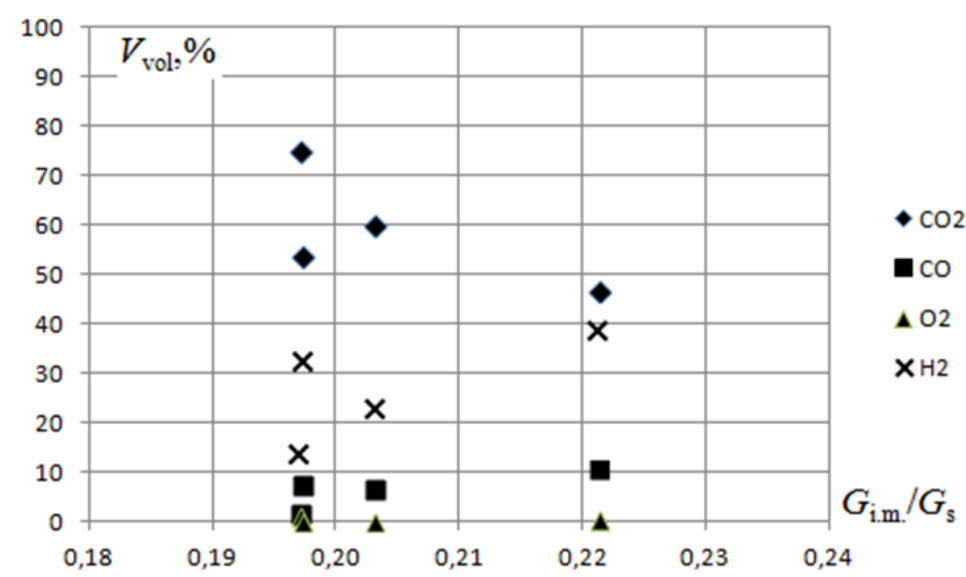

Figure 2. Concentration of gas mixture components $\left(V_{\mathrm{vol}}\right)$ vs the ratio of flow rates of gas mixture $\left(G_{\mathrm{i} . \mathrm{m} .}\right)$ and steam $\left(G_{\mathrm{s}}\right)$

Here, obtained concentrations of reaction product components are shown for different ratios of the mass flow rate of gas mixture $\left(G_{\mathrm{i} . \mathrm{m}}\right)$ to the mass flow rate of steam $\left(G_{\mathrm{s}}\right)$. The amount of steam supplied to the steam superheater was constant.

According to measurement results, it can be assumed that for $G_{\mathrm{i} . \mathrm{m}} / G_{\mathrm{s}}=0.197$, methane oxidizes by equation (1). Then, with an increase in the flow rate of gas mixture, we can see an insignificant shift towards reactions (2)-(4).

\section{Conclusions}

Combustion of $\mathrm{CH}_{4}: \mathrm{O}_{2}$ mixture in the medium of low-potential steam was studied experimentally. The range of stable mixture combustion at the studied values of gas mixture and steam characteristics was determined. The superheated steam-gas mixture with the temperature of $480-600^{\circ} \mathrm{C}$ and pressure close to the atmospheric one was obtained. An increase in the temperature of steam-gas mixture occurs with an increase in the portion of supplied gas.

The studies were financially supported by the Russian Ministry of Education and Science; Unique Identifier of Applied Scientific Research (Project) RFMEFI57614X0049.

\section{References}

1. S. V Dubovskiy, Energy Problems of stagnation, 8, 7 (2008)

2. T. Boushaki, Y. Dhué, L. Selle, B. Ferret, T. Poinsot, International Journal of Hydrogen Energy, 37 (11), 9412 (2012)

3. R. A. Makhmutov, Bashkirskiy Khmicheskii Jurnal, 17 (3), 137 (2010) 